\title{
Clinical Predictors of Weight Gain in Early Breast Cancer Survivors
}

\author{
Su-Ying $\mathrm{Yu}^{1,2} \&$ Chii-Ming $\mathrm{Chen}^{3}$ \\ ${ }^{1}$ School of Nursing, National Taipei University of Nursing and Health Sciences, Taipei, Taiwan \\ ${ }^{2}$ Department of Nursing, Koo Foundation Sun Yat-Sen Cancer Center, Taipei, Taiwan \\ ${ }^{3}$ Office of Vice and department of General surgery, Koo Foundation Sun Yat-Sen Cancer Center, Taipei, Taiwan \\ Correspondence: Su-Ying Yu, School of Nursing, National Taipei University of Nursing and Health Sciences, \\ Taipei, Taiwan. Tel: 886-937-548-210.
}

Received: March 29, 2021

Accepted: May 10, 2021

Online Published: May 20, 2021

doi:10.20849/ijsn.v6i2.888

URL: https://doi.org/10.20849/ijsn.v6i2.888

\begin{abstract}
Aim: To identify risk factors for weight gain after two years of a breast cancer diagnosis.

Background: Obesity in survivors of early-stage breast cancer has been associated with high disease recurrence rates and lower overall survival rates. Continuous weight gain is an indisputable phenomenon. Identifying factors at the early diagnosis and treatment phase that are associated with weight gain at 2 years later may help to develop further intervention for prevention obesity in breast cancer survivors.
\end{abstract}

Method: A retrospective study was designed to review medical records of 1901 early-stage breast cancer survivors. Extracted data included demographics, past medical history, cancer treatment, tumor characteristics, BMI at diagnosis, and 24-month weights.

Results: The sample had a mean age $50.3( \pm 10.7)$. Most of them were premenopausal, stage II and BMI ranging from 18.5 to $24 \mathrm{~kg} / \mathrm{m}^{2}$ at diagnosis. A majority of them received mastectomy $(65.9 \%)$, chemotherapy $(68.8 \%)$, radiotherapy $(64.6 \%)$ and hormone therapy (63\%). At 24 months after surgery, the breast cancer patients gained a mean of $0.4 \mathrm{~kg}$; but $21.6 \%$ of them gained $5 \%$ or more. The breast cancer survivors those who were premenopausal at diagnosis, less-than-high-school education, receiving adriamycin agent, cyclophosphamide agent, and gaining $5 \%$ or more weight after surgery had significant higher risk to gain $5 \%$ or more at 2 years after diagnosis.

Conclusion: Findings from our study suggested that the premenopausal women or those who receive less formal education have higher risk to gain weight after breast cancer treatment. Engagement to healthy weight management for these high risk groups are warranted

Keywords: early-stage breast cancer, weight gain, chemotherapy

\section{Introduction}

In 2020 American Cancer Society, an estimated 276,480 new breast cancer will be diagnosed with a relative survival rate of up to $80 \%$ after 15 years (Siegel, Miller, \& Jemal, 2020). Early diagnosis and advances of neo-adjuvant, adjuvant chemotherapy and hormone therapy utility greatly improve early breast cancer survival rates. Along with improved disease survival, advances in breast treatment have brought with them a considerable degree of adverse effects. Most of breast cancer survivors have been found to be overweight or obese (Ewertz et al., 2012; Imayama et al., 2013; Ortiz-Mendoza, de-la-Fuente-Vera, \& Pérez-Chávez, 2014), especially early-stage breast cancer (EBC) survivors with significant weight gain after adjuvant treatment (Arce-Salinas et al., 2014; Vargas-Meza et al., 2017), hormone therapy (Kai Gu et al., 2010; Lorizio et al., 2012)..The relationship between breast cancer recurrence and weight change was first investigated by Abe et al (Abe, Kumagai, Kimura, Hirosaki, \& Nakamura, 1976); and chemotherapy(Jung, Kim, \& Chung, 2020; Schvartsman et al., 2017; M. Van den Berg et al., 2017) was associated with weight gain, especially when cyclophosphamide, methotrexate and 5-fluorouracil (CMF) regiment were more obvious ( Jung et al., 2020; Schvartsman et al., 2017; M. Van den Berg et al., 2017). The problem of weight gain has been around for a long time and it is still found that almost two years after the diagnosis, the weight has increased by 1.9 to $5.1 \mathrm{~kg}$ (Makari-Judson, Braun, Jerry, \& Mertens, 2014; Reddy et al., 2013), which shows that this problem still exists and is serious. In the meta analysis review, weight gain during chemotherapy about $2.7 \mathrm{~kg}$, high heterogeneity $(\mathrm{I})^{2} 94.2 \%$ and the stratified 
analysis showed that the weight of all classes increased without low heterogeneity. (M. M. G. A. van den Berg et al., 2017). Significant weight gain before 2000, the publication problem after 2000 still exists and has not improved.

Post diagnosis weight gains of 2.5 to $6.7 \mathrm{~kg}$ was reported in Western countries (Lankester, Phillips, \& Lawton, 2002; V. Vance, M. Mourtzakis, L. McCargar, \& R. Hanning, 2011) and almost occurred in the 12 months after diagnosis and during adjuvant treatment period (C. L. Rock \& Demark-Wahnefried, 2002; O. Trédan et al., 2010; M. Van den Berg et al., 2017) or Even as long as five years (Schmidt, Wiskemann, \& Steindorf, 2018). Weight gain during adjuvant treatment may increase the risk of recurrence and mortality (Chan et al., 2014; Li et al., 2019), and decrease survival (Kroenke, Chen, Rosner, \& Holmes, 2005; Shang et al., 2021) and overall health (Caan et al., 2012; Hamer \& Warner, 2017; Nichols et al., 2009; M. Van den Berg et al., 2017).

Weight gain is a common phenomenon among breast cancer survivors who receiving adjuvant chemotherapy (Jung et al., 2020; Olivier Trédan et al., 2010), longer duration of treatment (M. Van den Berg et al., 2017), being premenopausal women (A. Gandhi et al., 2019; Wang, Cai, Wang, Zhang, \& Zhang, 2014). Other factors included in age (Chen et al., 2011; da Silva, Weiderpass, Licaj, Lissner, \& Rylander, 2018; Nyrop et al., 2017), advance stage (Caan et al., 2008; N. Saquib et al., 2007), and decreasing of physical activity (da Silva et al., 2018; Ferioli et al., 2018; Harvie, Howell, Thatcher, Baildam, \& Campbell, 2005; Sander, Wilson, Izzo, Mountford, \& Hayes, 2012), increasing of energy intake(De Vries et al., 2017; Katan \& Ludwig, 2010). Physical activity and eating habits are long-term behaviors that cannot be changed in a short time. The relative weight gain is also the result of chronic energy accumulation or reduced energy consumption. Most existing research on weight gain factors of EBC survivors showed prior factors and inconsistent founding developed by Korean, Canada research (Campbell, Lane, Martin, Gelmon, \& McKenzie, 2007; Han et al., 2009).

In Asian populations have different associations between BMI, percentage of body fat, and health risks than European populations have. Asian people with a high risk of type 2 diabetes and cardiovascular disease is substantial at BMIs lower than the existing WHO cut-off point for overweight $(25 \mathrm{~kg} / \mathrm{m} 2)$ (World Health Organization. Regional Office for the Western, 2000). The past research may partly explain the large variables in weight change such as longer duration (Heideman, Russell, Gundy, Rookus, \& Voskuil, 2009; Cheryl L. Rock et al., 1999; V Vance, M Mourtzakis, L McCargar, \& R Hanning, 2011), a regiment of chemotherapy (such as cyclophosphamide, anthracyclines, taxane-based) (Kroenke et al., 2005; Nichols et al., 2009; Olivier Trédan et al., 2010), menopausal status (Caan et al., 2012; Liu, Lin, Miaskowski, Chen, \& Chen, 2017), time of weight measurement. Despite the strong evidence linking obesity and inactivity to $\mathrm{BC}$ outcomes, and $\mathrm{BC}$ survivors with excess weight still developed. Strategies are needed to disseminate weight management and physical activity programs to these populations. If clinical predictors provided the suitable right time to intervene and weight gain should also be prevented by some weight management strategies. Many researches have discussed the causes or the treatment role of weight gain, but ignored the importance of early detection and prevention. If the clinicians can use the predictors to apply early risk assessment and planning, it may decline weight-related problems.

According to the ideal weight range defined by the WHO (BMI $18.5-24.9 \mathrm{~kg} / \mathrm{m}^{2}$ ) (World Health Organization. Regional Office for the Western, 2000), the risk of all-cause mortality in Taiwan people will increase with BMI, and the relative risk of overweight and obesity will increase significantly. The BMI value exceeds $25 \mathrm{~kg} / \mathrm{m}^{2}$, each increase in the value of 1 unit is relative to the relative mortality risk from all causes increase by $9 \%$.The Asians have more body fat than whites and have a higher risk of cardiovascular disease (Goh \& Hart, 2018; Misra et al., 2018). Premenopausal overweight and obesity in Asian women are associated with breast cancer (Nindrea, Aryandono, Lazuardi, \& Dwiprahasto, 2019) and the incidence of BC in Asia women peaks between 40 and 50 years old (Gomez, Yao, Kushi, \& Kurian, 2019). By cancer registry annual report in Taiwan, female breast cancer, 14,217 new diagnoses were documented in 2018 (Health promotion administration ministry of health and welfare Taiwan, 2020) and relative survival rate was $85 \%$ after 5 years (Yip, 2009). When the proportion of breast cancer patients who are overweight before surgery is as high as $39.3 \%$ (Feng et al., 2018), the issue of weight gain has become a very important issue.

Thus, the purposes of this study were to explore the predictors of weight gain in EBC survivors two years after diagnosis. The findings can contribute to assist breast cancer clinicians making the decision of weight management for high risk patients, help patients actively participate in weight management and EBC rehabilitation program earlier.

\subsection{Background}

Changes in body weight associated with cancer treatment (Vagenas et al., 2015) for a number of decades. The key research reports that 50-96\% of EBC patient experience weight gain during treatment phase (Ashu Gandhi et 
al., 2019) and other research showed that weight change persisted progressively for several years after diagnosis, even in patients with weight maintaining during treatment phase (Wendy Demark-Wahnefried et al., 2001). This aspect was also observed in a longitudinal study, which the risk of weight gain was positively related to the time elapsed after diagnosis (Sedjo et al., 2014). The risk factors associated with the weight gain of EBC have been investigated by several researchers. Several investigations report that the weight gain may be attributed by the effects of cancer treatment such as chemotherapy, endocrine therapy (ET) (Grace Makari-Judson, Braun, Jerry, \& Mertens, 2014; Sedjo et al., 2014). However, little has been explored about the association of other clinical factors, such as surgery and tumor characteristics, and other social factors, such as education that may denote as competency for healthy weight management.

\subsubsection{Weight Gain}

Women tend to gain weight after breast cancer diagnosis and during chemotherapy, which may increase risk of poor outcomes. EBC survivors BMI increase of more than $0.5 \mathrm{~kg} / \mathrm{m}^{2}$ compared to maintaining BMI was marginally associated with increased loco-regional recurrence risk (HR: $2.53 ; 95 \% \mathrm{CI}, 1.18-5.45 ; \mathrm{P}=0.017$ ) (Schvartsman et al., 2017). EBC survivors with overweight or obese measured as $68 \%$ at 72 months after surgery (Vagenas et al., 2015) and overweight or obese are a severe health issue for EBC survivors. Previous research on weight change and health implications reported that a weight change of greater than $5 \%$ might be considered clinically relevant (Ball, Brown, \& Crawford, 2002; Caan et al., 2006).

\subsubsection{Chemotherapy}

Receipt of chemotherapy has been linked to weight gain since the 1970's in EBC survivorship (W. Demark-Wahnefried, Winer, \& Rimer, 1993) and weight changes excess 8-10 kg with CMF regiment, prednisone for one year regiment (Puckett, Gabbar, \& Bokhari, 2018; Verhaegen \& Van Gaal, 2019). The CMF regiment showed weight gain worse than others regiment (M. Van den Berg et al., 2017; Park et al., 2018) and taxane, anthracycline regiment are associated with less weight gain (M. Van den Berg et al., 2017). However, premenopausal women receiving taxanes/anthracycline regimen chemotherapy with significant weight gain on different study (Ashu Gandhi et al., 2019) and it shows that adjuvant chemotherapy regimen have different conclusion, founding on weight gain problems. Impacting weight gain after diagnosis and included chemotherapy regiment, premenopausal, ET, younger, initially weight or BMI at diagnosis. EBC weight change with greater than $5 \%$ of their baseline weight at 18 months (Chen et al., 2011; K. Gu et al., 2010) and weight change factor as previous studies except socio-demographics, lifestyle factors.

\subsubsection{Endocrine Treatment}

In current clinical treatment guidelines recommended that adjuvant therapy includes endocrine therapy in postmenopausal EBC at least five years to improve their overall prognosis and survival. (Dowsett et al., 2010; Schiavon \& Smith, 2014). For postmenopausal E BC survivors, ET was recommended with aromatase inhibitor (AI) (Eisen et al., 2015; Taylor \& Muss, 2010), exemestane, anastrozole, or letrozole (Burstein, Griggs, Prestrud, \& Temin, 2010) and tamoxifen or an AI plus was suggested to premenopausal survivors. It is believed that long-term ET contributes to EBC weight change; but conflicting and inconsistent findings are reported (Howell et al., 2005; Saquib et al., 2007). Further studies are needed.

\subsubsection{Initially Body Weight or BMI}

Chemotherapy was strongly significantly associated with EBC weight gain and only $10 \%$ of EBC survivors returned to their pre--diagnosis weight after follow-up (Saquib et al., 2007). Lower BMI at diagnosis showed higher risk for greater subsequent weight gain after treatment (Ashu Gandhi et al., 2019). EBC women weight gain was significantly associated with BMI and weight at diagnosis.

\subsubsection{Surgical Node Dissection or Hormone Receptors}

Patient and treatment related weight gain occurred multicollinearity and mastectomy, stage, node dissection presented significant in separate multivariable models of adjuvant treatment (Nyrop et al., 2017). EBC survivor weight gain associations were observed between weight change and tumor stage but not associated with nodal stage, grading, hormone receptor status, or histologic cell subtype (Mutschler et al., 2018).

\subsubsection{Menopausal Status}

The weight gain observed in health women or undergoing menopause and a prospectively studies showed aged 45 to 55 years gained $0.79 \mathrm{~kg}$, aged 55 years and older lost weight(Williamson, Kahn, Remington, \& Anda, 1990). In a prospective study, a third of premenopausal EBC underwent adjuvant chemotherapy with significant weight gain and over 40\% EBC developed central obesity at 12 months after diagnosis (A. Gandhi et al., 2019). Another 
long term study reported premenopausal EBC with weight gain of $\geq 5 \%$ after 5 years of ET and premenopausal of EBC patient at diagnosis were 1.4 times then women who were postmenopausal at diagnosis (Mutschler et al., 2018; Raghavendra et al., 2018). In the new publication, it can be seen that in the first 2 years of breast cancer survivors, $49 \%$ of premenopausal survivors and 38\% of postmenopausal survivors still account for a large proportion of their body weight $>2 \mathrm{~kg}$ after two years of treatment (Nyrop et al., 2018). Women's menopausal status included variable list.

\section{Method}

\subsection{Aim}

The aim of the study was to identify factors that are associated with the development of weight gain greater than $5 \% 2$ years after surgery for early-stage breast cancer.

\subsection{Design}

This study was based on a retrospective cohort. Data were collected from electronic medical records of early-stage breast cancer survivors at a cancer center in northern Taiwan.

\subsection{Participants}

All patients with newly diagnosed early-stage breast cancer, who were diagnosed, treated and followed up at the research institute for two years, were screened for this study. The recruitment of patients was based on the following criteria: (1) stage 0 to III breast cancer was confirmed by tissue diagnosis and deemed operable, (2) surgical intervention for breast cancer with regular follow-up care at the center, and (3) age of 18 to 75 years at the time of diagnosis. The exclusion criteria were (1) history of multiple cancers, (2) recurrent or metastatic disease, (3) lack of weight or height records at diagnosis or during follow-up, and (4) history of renal or heart failure. A total of 1956 patients' medical records with newly diagnosed breast cancer and have had follow-up care for 2 years were extracted between 2010 and 2014.Of these, the study excluded 55 patients, because they either had incomplete weight or height data after surgery or loss follow up after surgery $(\mathrm{n}=47)$, passed away (n $=2)$, received adjuvant cancer treatment or follow-up care at another hospital $(\mathrm{n}=7)$, were undergoing hemodialysis treatment $(\mathrm{n}=1)$. The final sample was 1901 patients with breast cancer (Figure1).

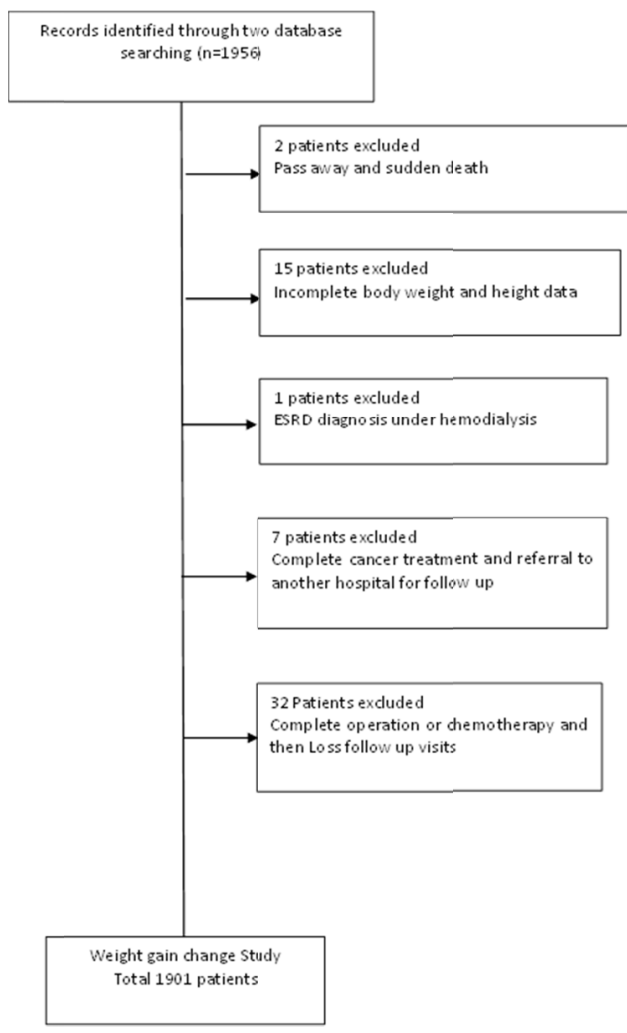

Figure 1. Recruitment of patients for study of weight gain 


\subsection{Data Collection}

Data pertaining to potential risk factors associated with the development of weight gain after surgery were extracted from electronic medical records. Clinical data included age at diagnosis (years), menopausal status at diagnosis, American Joint Committee on Cancer (AJCC) stage (I, II, III, 0), joint estrogen receptor(ER)/progesterone receptor (PR)/Her-2 status, surgery method(wide excision, mastectomy), adjuvant therapy (none, chemotherapy, cortisol agent, radiotherapy, endocrine treatment) and chronic personal medical history (diabetes, hypertension, dyslipidemia). Sociodemographic at diagnosis were also documented, including education and menopausal status. The weight and height of patients were obtained from their records at baseline before surgery, and 24 months after surgery. While the standard practice of this center, weight is measured and recorded by nursing staff. Nursing staff are required to weigh patients in light clothing without shoes, accessories, or additional items on their person. The body weight in $\mathrm{kg}$, one decimal. The uniform weight machine used at the hospital is regularly adjusted by the Public Works Department for precise measurement.

\subsection{Ethical Considerations}

Research was approved by the internal review board of the hospital (2011104A) .

\subsection{Data Analysis}

Statistics were performed with SPSS 23.0 for Windows. The $p$ value less than 0.05 indicate significant difference. Multivariate logistic regression was used to analyze significant factors in univariate analysis. As considering to test for the gap of previous studies, education and endocrine therapy were still included into adjusted model in multivariate analysis, though they did not yield significant difference in univariate analysis. Weight gain was grouped into one of two categories $(<5 \%$ and $\geq 5 \%)$. The weight change (percentage) before surgery and 24 months after surgery was calculated as $100 \times$ (weight at 24 months after surgery-weight before surgery) $\div$ (weight before surgery).

\subsection{Validity, Reliability and Rigour}

The validity and reliability were ensured via a rigorous process of data collection from e-medical records. A standardized protocol of collecting patient's personal information, disease, treatment and weight from patients' e-medical records was established by the research team, and was verified for its content availability, accuracy and feasibility by one nursing research, one breast cancer nurse practitioner and one medical informatics professional. The researcher proceeded to collect the data after a series of training, verification and test-retest process. She was trained by the rest of research team members. A performance test was conducted to check the concordance of data collection process with the protocol during the training section. Finally, the information from the first 10 medical records were re-collected two-week apart to check the test-retest reliability; and the agreement between the two times of data collection reached to $100 \%$ of 24 items.

\section{Results}

\subsection{Baseline and Treatment Characteristics of Patients}

All woman included in this study ( $\mathrm{n}=1901)$ and clinical and tumor characteristics of the study population all shown (table 1). Mean age at surgery was $50.3( \pm 10.7)$ years. Regarding education level, 566 patients $(30.1 \%)$ had a junior high school degree, 590 patients $(31.4 \%)$ had a high school degree, and 723 patients $(38.5 \%)$ had a college degree or higher. (Participants had more than a high school education). A total of 1091 patients (57.6\%) were undergoing menopause before surgery, and 806 patients $(42.4 \%)$ were postmenopausal. In total, 648 patients (34.1\%) underwent wide excision, and 1253 patients $(65.9 \%)$ underwent mastectomy. In total, 864 (45.4\%) patient had DCIS or stage I, 1037 patients (54.6\%) stage II, III disease, 1359 (71.5\%), 1144 (60.2\%) tested positive for estrogen, progestogen receptors, and $1255(66 \%)$ tested positive for Her-2 receptors. The majority received chemotherapy (68.8\%), radiation therapy $(64.6 \%)$ and $63 \%$ of participants received hormone therapy. At the time of breast cancer surgery, $42.1 \%$ of women was overweight or obese (BMI $\geq 24 \mathrm{~kg} / \mathrm{m} 2)$. The mean body weight before surgery was $58.2 \mathrm{~kg}$ (standard deviation [SD] 9.5) and mean body weight was $58.6 \mathrm{~kg}$ (SD 9.5) 24 months after surgery. However, $22 \%$ of patients' weight gained more than $5 \%$ at the second years. The weight gain $<5 \%$ groups and $\geq 5 \%$ groups reached the crossover point in the first year after the operation (Figure 2). The weight gain of less than 5\% groups developed decreased slightly, and weight gain of more than or equal to $5 \%$ groups developed increased slightly and two groups resulting in two weight gain trend. 
Table 1. Weight gain and clinical characteristics

\begin{tabular}{|c|c|c|c|c|c|}
\hline & & & $\begin{array}{l}\text { 24-month } \\
\text { Weight Gain }\end{array}$ & & \\
\hline & & & & $\geq 5 \%$ & \\
\hline & & $(\mathrm{n}=1901)$ & $(\mathrm{n}=1490)$ & $(\mathrm{n}=411)$ & $\mathrm{p}$ \\
\hline Age at diagnosis, & & & & & $<0.0001$ \\
\hline & mean(SD) & $50.3(10.7)$ & $50.9(10.7)$ & $48.4(10.7)$ & \\
\hline \multicolumn{6}{|l|}{ Weight } \\
\hline \multicolumn{6}{|l|}{ At diagnosis } \\
\hline & mean(SD) & $58.2(9.5)$ & $59.1(9.7)$ & $55.3(8.0)$ & \\
\hline \multicolumn{6}{|l|}{24 months } \\
\hline & mean(SD) & $58.6(9.5)$ & $58.1(9.6)$ & $60.3(8.9)$ & \\
\hline \multirow[t]{4}{*}{ Baseline BMI } & & & & & $<0.0001$ \\
\hline & $<18.5$ & $73(3.8)$ & $53(3.6)$ & $20(4.9)$ & \\
\hline & $18.5-24$ & $1027(54)$ & $750(50.3)$ & $277(67.4)$ & \\
\hline & $>=24$ & $801(42.1)$ & $687(46.1)$ & $114(27.7)$ & \\
\hline \multicolumn{6}{|l|}{ AJCC stage } \\
\hline & DCIS/ I & $864(45.4)$ & $685(46)$ & $179(43.6)$ & \\
\hline & II/ III & $1037(54.6)$ & $805(54)$ & $232(56.4)$ & \\
\hline \multirow[t]{3}{*}{ Menopausal status } & & & & & $<0.001$ \\
\hline & postmenopausal & $806(42.4)$ & $671(45)$ & $135(32.8)$ & \\
\hline & premenopausal & $1094(57.6)$ & $819(55)$ & $276(67.2)$ & \\
\hline \multicolumn{6}{|l|}{ Education } \\
\hline & $<$ high school & $566(30.1)$ & $441(29.6)$ & $125(30.4)$ & \\
\hline & high school & $590(31.4)$ & $473(31.7)$ & $117(28.5)$ & \\
\hline & $\geq$ college & $723(38.5)$ & $556(37.3)$ & $167(40.6)$ & \\
\hline \multirow[t]{3}{*}{ Past medical history } & & & & & 0.02 \\
\hline & None & $1463(77)$ & $1129(75.8)$ & $334(81.3)$ & \\
\hline & Yes & $438(23))$ & $361(24.2)$ & $77(18.7)$ & \\
\hline \multirow[t]{3}{*}{ Breast surgery } & & & & & $\mathrm{NS}$ \\
\hline & WE & $648(34.1)$ & $518(34.8)$ & $130(31.6)$ & \\
\hline & Mastectomy & $1253(65.9)$ & $972(65.2)$ & $281(68.4)$ & \\
\hline \multicolumn{6}{|l|}{ ER receptor } \\
\hline & Negative & $542(28.5)$ & $433(29.1)$ & $109(26.5)$ & \\
\hline & positive & $1359(71.5)$ & 1057(70.9) & $302(73.5)$ & \\
\hline \multicolumn{6}{|l|}{ PR receptor } \\
\hline & Negative & $757(39.8)$ & $590(39.6)$ & $167(40.6)$ & \\
\hline & positive & $1144(60.2)$ & $900(60.4)$ & $244(59.4)$ & \\
\hline \multicolumn{6}{|l|}{ HER2 receptor } \\
\hline & Negative & $646(34)$ & $525(35.2)$ & $121(29.4)$ & \\
\hline
\end{tabular}




\begin{tabular}{|c|c|c|c|c|c|}
\hline & positive & $1255(66)$ & $965(64.8)$ & $290(70.6)$ & \\
\hline \multicolumn{6}{|l|}{ Chemotherapy } \\
\hline & No & 594(31.7) & $486(32.6)$ & $108(26.3)$ & \\
\hline & Yes & $1307(68.8)$ & $1004(67.4)$ & $303(73.7)$ & \\
\hline \multirow[t]{3}{*}{ Adriamycin agent } & & & & & 0.03 \\
\hline & No & $679(35.7)$ & $551(3.7)$ & $128(6.8)$ & \\
\hline & Yes & $1222(64.3)$ & $939(63)$ & $283(20.2)$ & \\
\hline \multicolumn{6}{|l|}{ Taxane-base agent } \\
\hline & No & $1328(69.9)$ & $1046(70.2)$ & $282(68.6)$ & \\
\hline & Yes & $573(30.1)$ & $444(29.8)$ & $129(31.4)$ & \\
\hline \multirow[t]{3}{*}{ Cyclophosphamide agent } & & & & & $<0.001$ \\
\hline & No & $662(73.5)$ & $649(43.6)$ & $132(32.1)$ & \\
\hline & Yes & $1239(65.2)$ & $841(56.4)$ & $279(67.9)$ & \\
\hline \multirow[t]{3}{*}{ Dexamethasone agent } & & & & & 0.01 \\
\hline & No & $599(31.5)$ & $490(33)$ & $109(26.5)$ & \\
\hline & Yes & $1302(68.5)$ & $1000(67)$ & $302(73.5)$ & \\
\hline \multicolumn{6}{|l|}{ Radiation } \\
\hline & No & $673(35.4)$ & $536(36)$ & $137(33.3)$ & \\
\hline & Yes & $1228(64.6)$ & $954(64)$ & $274(66.7)$ & \\
\hline \multicolumn{6}{|l|}{ Endocrine therapy } \\
\hline & None & $703(37)$ & $560(37.6)$ & $143(34.8)$ & \\
\hline & Yes & $1198(63)$ & $930(62.4)$ & $268(65.2)$ & \\
\hline
\end{tabular}

Note: DCIS=ductal carcinoma in situ; ER = estrogen receptor; PR = progesterone receptor; HER2 = human epithelial growth factor-2; $\mathrm{WE}=$ wide excision

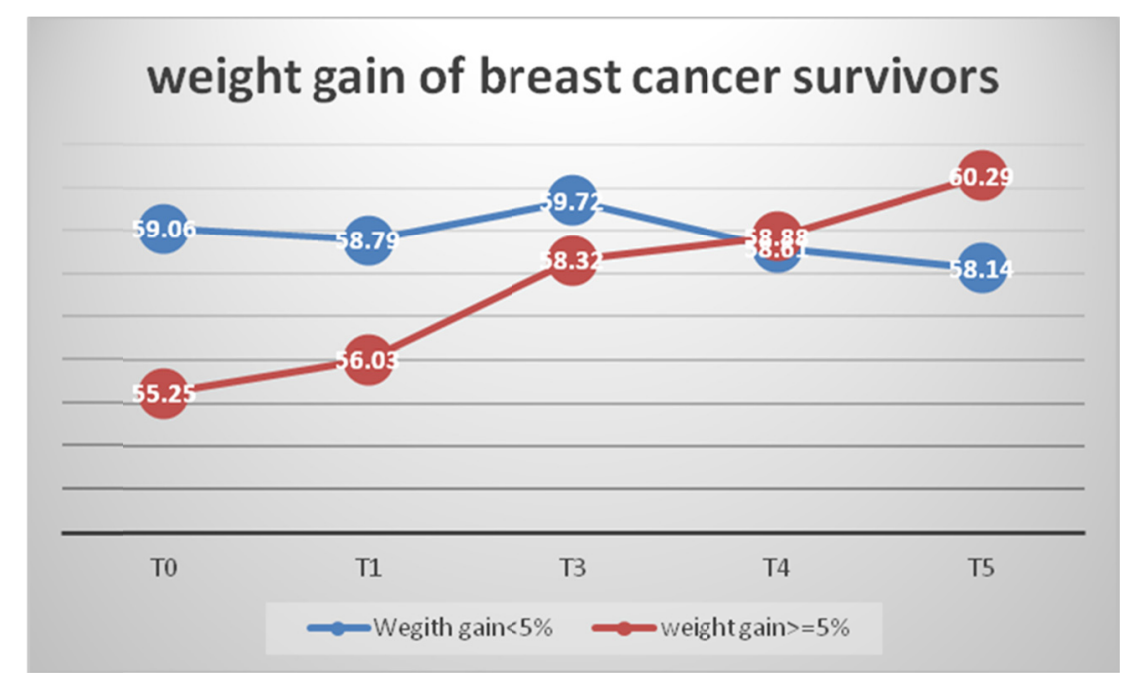

Figure 2. BC survivor weight gain $>=5 \%$ and $<5 \%$ curve

Note: $\mathrm{T} 0=$ Baseline weight, $\mathrm{T} 1=1$ month after diagnosis, $\mathrm{T} 2=3$ months, $\mathrm{T} 3=5$ months, $\mathrm{T} 4=1$ year, $\mathrm{T} 5=2$ years after diagnosis 


\subsection{Correlates of Weight Gain}

The univariate analysis of associations between weight gain, clinical and participant characteristics factors were shown in Table 2. In univariate analysis, age at surgery $(\mathrm{OR}=0.978, \mathrm{p}=.0001)$, menopausal status $(\mathrm{OR}=1.675$, $\mathrm{p}=.0001)$, personal medical history $(\mathrm{OR}=0.72, \mathrm{p}=.02)$, baseline $\mathrm{BMI} \geq 24(\mathrm{OR}=0.44, \mathrm{p}=.003)$, baseline weight $(\mathrm{OR}=0.95, \mathrm{p}=.001)$, weight gain $\geq 5 \%$ after one month $(\mathrm{OR}=4.745, \mathrm{p}=.0001)$, chemotherapy $(\mathrm{OR}=1.358$, $\mathrm{p}=.01)$, adriamycin-based regiment $(\mathrm{OR}=1.297, \mathrm{p}=.029)$, taxane-based regiment $(\mathrm{OR}=1.078, \mathrm{p}=.535)$, cyclophosphamide-based regiment $(\mathrm{OR}=1.63, \mathrm{p}=.0001)$, dexamethoasone agent $(\mathrm{OR}=1.358, \mathrm{p}=.01)$ were associated with weight gain.

\subsection{Multivariate Model of Weight Gain}

Before the process of multivariate statistics, we evaluated weight gain and sociodemographic characteristic factors, clinical factors and we checked for multicollinearity first. The variance inflation factors (VIF) and condition index (CI) were used for detection of potential clinical multicollinearlity problems between weight gain and variables. Due to multi-collinearity between age and menopausal status at diagnosis, and among adriamycin, cyclophosphamide, taxane and dexamethasone, only menopausal status, Adriamycin and cyclophosphamide were included for adjusted model.

We entry baseline BMI, education level, A agents, $\mathrm{C}$ agents, personal medical history, weight gain $\geq 5 \%$ after one month, menopausal status, hormone therapy in the final model. Thus, eight factors derived from univariate analysis into the multivariate model simultaneously. The overall final model exhibited a good fit with well explanation date $\left(\chi^{2}=190.28, \mathrm{p}=<0.0001\right.$, Nagelkerke $\left.\mathrm{R}^{2}=.148\right)$. In multivariate logistic regression analysis disclosed menopausal status ( $\mathrm{OR}=1.48, \mathrm{p}=.03$ ), education level (high school $\mathrm{OR}=.611, \mathrm{p}=.003$; college $\mathrm{OR}=.679$, $\mathrm{P}=.016)$, chemotherapy with $\mathrm{A}(\mathrm{OR}=.584, \mathrm{p}=.011)$, C agent $(\mathrm{OR}=2.0, \mathrm{p}=.001)$ (Table 3$)$.

Table 2. Univariate analysis for associations between clinical characteristics and 5\% 24-month weight gain

\begin{tabular}{llll}
\hline Variable & OR & $95 \% \mathrm{CI}$ & $p$ \\
\hline Age at diagnosis & 0.978 & $0.968-0.988$ & $<0.0001$ \\
\hline Weight & & & \\
\hline at diagnosis & 0.951 & $0.937-0.964$ & $<0.0001$ \\
\hline 24 months & 1.023 & $1.012-1.035$ & $<0.0001$ \\
\hline
\end{tabular}

\begin{tabular}{|c|c|c|c|c|}
\hline \multicolumn{5}{|l|}{ BMI at diagnosis } \\
\hline & $<18.5$ & ref & & \\
\hline & $\geq 18.5<24$ & 0.979 & $0.575-1.667$ & 0.937 \\
\hline & $\geq 24$ & 0.440 & $0.253-0.763$ & 0.003 \\
\hline \multicolumn{5}{|l|}{ AJCC stage of BC } \\
\hline & DCIS/ I & ref & & \\
\hline & II/III & 1.103 & $0.885-1.374$ & 0.383 \\
\hline \multicolumn{5}{|l|}{ Menopausal status } \\
\hline & postmenopausal & ref & & \\
\hline & premenopausal & 1.675 & $1.331-2.108$ & $<0.0001$ \\
\hline \multicolumn{5}{|l|}{ Education } \\
\hline & $<$ high school & ref & & \\
\hline & high school & 0.873 & $0.657-1.159$ & 0.346 \\
\hline & $\geq$ college & 1.060 & $0.814-1.379$ & 0.666 \\
\hline \multicolumn{5}{|l|}{ Past medical history } \\
\hline & None & & & \\
\hline
\end{tabular}




\begin{tabular}{|c|c|c|c|c|}
\hline Variable & & OR & $95 \% \mathrm{CI}$ & $p$ \\
\hline & Yes & 0.721 & $0.548-0.949$ & 0.020 \\
\hline \multicolumn{5}{|c|}{ Breast surgery } \\
\hline & \multicolumn{4}{|l|}{ WE } \\
\hline & Mastectomy & 1.152 & $0.912-1.455$ & 0.235 \\
\hline \multicolumn{5}{|c|}{ ER receptor } \\
\hline & \multicolumn{4}{|l|}{ Negative } \\
\hline & positive & 0.550 & $0.1-3.016$ & 0.492 \\
\hline \multicolumn{5}{|c|}{$\mathrm{PR}$ receptor } \\
\hline & \multicolumn{4}{|l|}{ Negative } \\
\hline & positive & 0.550 & $0.100-3.016$ & 0.492 \\
\hline \multicolumn{5}{|c|}{ HER2 receptor } \\
\hline & \multicolumn{4}{|l|}{ Negative } \\
\hline & positive & 1.419 & $0.775-2.599$ & 0.257 \\
\hline \multicolumn{5}{|c|}{ Chemotherapy } \\
\hline & \multicolumn{4}{|l|}{ None } \\
\hline & Yes & 1.358 & $1.063-1.736$ & 0.014 \\
\hline \multicolumn{5}{|c|}{ Adriamycin agent } \\
\hline & \multicolumn{4}{|l|}{ No } \\
\hline & Yes & 1.297 & $1.027-1.639$ & 0.029 \\
\hline \multicolumn{5}{|c|}{ Taxane-base agent } \\
\hline & \multicolumn{4}{|l|}{ No } \\
\hline & Yes & 1.078 & $0.851-1.365$ & 0.535 \\
\hline \multicolumn{5}{|c|}{ Cyclophosphamide agent } \\
\hline & \multicolumn{4}{|l|}{ No } \\
\hline & Yes & 1.631 & $1.295-2.055$ & $<0.0001$ \\
\hline \multicolumn{5}{|c|}{ Dexamethasone agent } \\
\hline & \multicolumn{4}{|l|}{ No } \\
\hline & Yes & 1.358 & $1.063-1.733$ & 0.01 \\
\hline \multicolumn{5}{|l|}{ Radiation } \\
\hline & \multicolumn{4}{|l|}{ None } \\
\hline & Yes & 1.124 & $0.892-1.415$ & 0.322 \\
\hline \multicolumn{5}{|c|}{ Endocrine therapy } \\
\hline & \multicolumn{4}{|l|}{ None } \\
\hline & Yes & 1.129 & $0.898-1.418$ & 0.300 \\
\hline
\end{tabular}

Table 3. Multivariate analysis for clinical predictors of weight gain at 24 months

\begin{tabular}{|c|c|c|c|c|}
\hline Variable & & Adju.OR & $95 \% \mathrm{CI}$ & $p$ \\
\hline \multicolumn{5}{|c|}{ BMI at Diagnosis } \\
\hline & $<18.5$ & ref & & \\
\hline & $18.5-24$ & 1.162 & $0.659-2.050$ & 0.604 \\
\hline
\end{tabular}




\begin{tabular}{|c|c|c|c|c|}
\hline & $>=24$ & 0.592 & $0.325-1.079$ & 0.087 \\
\hline \multicolumn{5}{|l|}{ Menopausal status } \\
\hline & postmenopausal & ref & & \\
\hline & premenopausal & 1.48 & $1.038-2.127$ & 0.03 \\
\hline \multicolumn{5}{|l|}{ Education } \\
\hline & $<$ high school & ref & & \\
\hline & high school & 0.611 & $0.443-0.843$ & 0.003 \\
\hline & $\geq$ college & 0.679 & $0.496-0.929$ & 0.016 \\
\hline \multicolumn{5}{|l|}{ Past medical history } \\
\hline & None & ref & & \\
\hline & YES & 1.081 & $0.784-1.490$ & 0.636 \\
\hline \multicolumn{5}{|l|}{ Adriamycin agent } \\
\hline & No & ref & & \\
\hline & Yes & 0.584 & $0.584-0.886$ & 0.011 \\
\hline \multicolumn{5}{|c|}{ Cyclophosphamide agent } \\
\hline & No & & & \\
\hline & Yes & 2.001 & $1.326-3.020$ & 0.001 \\
\hline \multicolumn{5}{|l|}{ Endocrine therapy } \\
\hline & None & & & \\
\hline & Yes & 0.945 & $0.735-1.213$ & 0.656 \\
\hline
\end{tabular}

\section{Discussion}

In this large,-cohort study, we disclosed twenty-two percent of EBC survivors gained body weight after surgery and the mean weight gain from surgery to 24 months after surgery was $5 \mathrm{~kg}$ in weight gain $\geq 5 \%$ group, weight loss $1 \mathrm{~kg}$ in weight gain $<5 \%$ group. Overall mean weight gained $0.4 \mathrm{~kg}$ only and the weight trends of the two groups are different. This study investigated risk factors associated with weight gain of EBC patient which the predictors factor of weight changes critical point. Fourteen potential factors were collected from 1901 EBC patient's e-medical records. This study used univariate logistic regression analysis of fourteen factors for making decision which factors was predictor of weight change. Most previous research evaluated weight gain in EBC only one year after diagnosis has found that the time of weight change occurs after $\mathrm{EBC}$ diagnosis, and even 10 years after diagnosis. The phenomenon of weight change continues to progress and the study looking for critical moment of weight change. This concept of prevention should be extension to blueprint for breast cancer care.

Studies have shown that breast cancer survivors gained significantly more weight from diagnosis to the third year of life in women with more advanced breast cancer, younger, postmenopausal, and less physically active age (da Silva et al., 2018; Nyrop et al., 2017; Schiavon \& Smith, 2014). Weight gain has been observed to occur after diagnosis (M. M. G. A. van den Berg et al., 2017) and associated with combined systemic treatment (Chen et al., 2011). Prevalence rates differ by country (Dow, Ferrell, Leigh, Ly, \& Gulasekaram, 1996; K. Gu et al., 2010; O. Trédan et al., 2010; Tremblay, Pérez, Ardern, Bryan, \& Katzmarzyk, 2005; V. Vance et al., 2011). Breast cancer survivors still have $32 \%$ of patients with weight problems until five years after diagnosis(Schmidt et al., 2018). The impact of the weight problem is very long-lasting. Although past studies have shown that the weight has stabilized two years after diagnosis. The study reveals that weight gain within 24 months after breast cancer surgery is common among Taiwanese women and sustained afterwards. An association with chemotherapy effects was observed in univariate analysis and multivariate analysis. In total, $21.6 \%$ of survivors gained more than $5 \%$ body weight from baseline to 24 months after surgery. This is like finding in the literature in the past that it is rare to return to the starting weight after gaining weight (Nazmus Saquib et al., 2007). This percentage is similar to those obtained in Western studies and weight issue associated with chronic disease was worth observance. 
In Korea study reported the significant decrease in average weight was mainly diagnosed after 12 months and the younger age group gained significant weight after 36 months (Min, Lee, Chung, \& Ahn, 2017). Some studies have found that the degree of weight gain caused by the use of different chemotherapy drug formulations is different. The adjuvant chemotherapy regimens incorporated anthracyclines and / or taxanes in the past few years and weight gain change was lesser than past. The current use of taxanes-based and other drugs still cause a slight weight gain problem and weight reverse after 1 year after chemotherapy (A. Gandhi et al., 2019).This issue must be time observation confirms the seriousness of this problem. In our study, the chemotherapeutics effects disappeared 12 months after surgery and this may be due to limited changes in body weight following the changes in hormone metabolism during early menopause.

The past literature appears regarding weight gain (A. Gandhi et al., 2019; Schvartsman et al., 2017) or weight maintenance in premenopausal women. Premenopausal status was related to weight gain in univariate analysis, and no significant difference was observed, which is consistent with other results (Irwin et al., 2005; Nyrop et al., 2018). Premature menopausal effects associated with weight change and fat tissue development were significant factors. Objective assessment of the menstrual periods of survivors of breast cancer was not completely accurate because it was based only on a case review. Menstrual status after chemotherapy might be affected, and the influence of menstrual status on subsequent weight changes might be underestimated (Kapoor, Collazo-Clavell, \& Faubion, 2017). Weight gain after chemotherapy was reported and even obesity is less prevalent in Asian countries (Chen et al., 2011; Kai Gu et al., 2010). In the reports of China, the weight gain was only $1.8 \mathrm{~kg}$, but $60 \%$ of breast cancer patients had abnormal BMI (Yeo et al., 2017). Those researchs showed that weight problems caused by treatment factors declining over time. That what factors still affect EBC women are the main points and even they implement weight management measures. In a few studies, whether physical symptoms and psychological distress have an impact on weight change and those studies also found that cancer patients with psychological disease significantly increased body change compared to patient without cancer (Vance, Mourtzakis, \& Hanning, 2019). Weight management attitudes and belief disordered eating and exercise behaviors and some factors was contributed excess weight as current, past history of weight and psychological distress (Pila, Sabiston, Taylor, \& Arbour-Nicitopoulos, 2018). Weight management failures associated with negative social experiences (Pila et al., 2018), inherently distress of weight management. EBC women reported feeling distress when these weight management were not successful or uncontrollable (Pedersen, Groenkjaer, Falkmer, Mark, \& Delmar, 2016).

Social pressure for weight management impacts EBC women attitudes and beliefs toward obesity, and caused by psychological distress, maladaptive eating patterns or behaviors (Carels et al., 2010). EBC patient suffered from systemic adjuvant treatment followed by 5 or 10 years ET, nature metabolic change, psychologic distress, impairment of quality of life. This finding highlights the nature of excess weight as a chronic condition after anti-cancer treatment that needs to be managed in light of other co-occurring illnesses. The present study extended current weight change exclusively as anti-cancer treatment induced, and highlights the considerable impact of pre-cancer weight concerns, and the nature of menopausal status. The weight problems worse than pre-diagnosis developed progressively and weight gain pathophysiology needs exploratory for evidence of weight management strategies. If initially identification of predictor risk factors was used on clinically assessment and it will be help for prevention of weight gain.

Weight gain after 2 years $\mathrm{EBC}$ women, it may be a highlighted the failure of weight loss or the cycle consistent of weight gain leading to subsequent distress, thwarting efforts for weight management. EBC survivors identified as high risk of developing weight gain after diagnosis may potentially benefit from interventions. Early assessment followed by health weight management can be helping health promotion early on high risk of EBC survivors. The research reported that a telephone based health lifestyle intervention program resulted in weight loss and demonstrated an opportune approach to weight management, improvements in metabolic parameters, and reduction in the risk of comorbidities for EBC survivor (Ligibel, Basen-Engquist, \& Bea, 2019).

\section{Limitation}

There are some limitations in this study and was a retrospective cohort study at the same cancer center. They may not be representative of the overall population of EBC survivors in Taiwan. Due to limitation in data collected by e-medical record and dietary intake, physical activity was not included this study. However, large sample sizes in this study and EBC patient, clinical characteristics, potential risk factors, cancer-related information for weight gain were included. Those data will provide us with reasonably predictable factors for weight change.

As a result, a negative effect on survival and disease recurrence was noted (Tessomboon \& Chompoonuch, 2019), 
but study method unfortunately cannot predict the magnitude of risk, which hindered identification of high-risk characteristics. This is one of the limitations in this study.

\section{Conclusion}

This study understands the predictors of weight change in 2 years after surgery for breast cancer. In the past literature, prediction models have been used for the recurrent, overall survivor of breast cancer. Rarely, they have been used to examine the changes in body weight using prediction models. The change in body weight is different from the Westerners. Although Asia women weight gains less than Westerners, the percentage of weight change is the same. It shows that problems of weight gain are more serious than the Westerners.

A weight change of more than $5 \%$ of initial body weight during adjuvant chemotherapy worsens the prognosis of patients with breast cancer in terms of overall survivors (OS) (Mutschler et al., 2018). EBC survivors should be advised to maintain a stable weight after diagnosis, receiving $\mathrm{C} / \mathrm{T}$ and should receive guidance on adequate nutrition and physical activity during $\mathrm{C} / \mathrm{T}$. Specific attention of weight change was considered

\subsection{Recommendations for Practice}

This study shed initially weight change after chemotherapy might have an influence on further weight change and also advised to attention in regard to their weight change during therapy. The etiology of weight change in $\mathrm{EBC}$ women is complex, this study suggests that changes in food intake and psychosocial challenges may play an important role for EBC women. Weight management strategies for EBC survivor has been conducted and considering the founding of the current study, weight management interventions may have to be sustained over a long-term period, especially in women who were diagnosed of EBC.

\subsection{Recommendations for Further Research}

This retrospective study on weight change predictors with newly EBC revealed that weight change associated with adjuvant cancer treatment at 5, 12 months after surgery. The influence of weight change has decreased after two years of diagnosis. What causes the weight change of EC survivors after diagnosis is still influential, which is worth further research and understanding it. In further, considering the fundamental challenges of weight management, improving weight related psychological effects should be a clinical priority to improve the well-being of women in survivorship.

\section{Acknowledgements}

We are grateful to Breast Cancer Research Foundation's sponsorship.

\section{References}

Abe, R., Kumagai, N., Kimura, M., Hirosaki, A., \& Nakamura, T. (1976). Biological characteristics of breast cancer in obesity. Tohoku J Exp Med, 120(4), 351-359. https://doi.org/10.1620/tjem.120.351

Arce-Salinas, C., Aguilar-Ponce, J. L., Villarreal-Garza, C., Lara-Medina, F. U., Olvera-Caraza, D., Alvarado Miranda, A., ... Mohar, A. (2014). Overweight and obesity as poor prognostic factors in locally advanced breast cancer patients. Breast Cancer Res Treat, 146(1), 183-188. https://doi.org/10.1007/s10549-014-2977-8

Ball, K., Brown, W., \& Crawford, D. (2002). Who does not gain weight? Prevalence and predictors of weight maintenance in young women. International Journal of Obesity, 26(12), 1570-1578.

Burstein, H. J., Griggs, J. J., Prestrud, A. A., \& Temin, S. (2010). American society of clinical oncology clinical practice guideline update on adjuvant endocrine therapy for women with hormone receptor-positive breast cancer. Journal of Oncology Practice, 6(5), 243-246.

Caan, B. J., Kwan, M. L., Hartzell, G., Castillo, A., Slattery, M. L., Sternfeld, B., ... Weltzien, E. (2008). Pre-diagnosis body mass index, post-diagnosis weight change, and prognosis among women with early stage breast cancer. Cancer Causes Control, 19(10), 1319-1328. https://doi.org/10.1007/s10552-008-9203-0

Caan, B. J., Kwan, M. L., Shu, X. O., Pierce, J. P., Patterson, R. E., Nechuta, S. J., ... Chen, W. Y. (2012). Weight change and survival after breast cancer in the after breast cancer pooling project. Cancer Epidemiol Biomarkers Prev, 21(8), 1260-1271. https://doi.org/10.1158/1055-9965.Epi-12-0306

Campbell, K. L., Lane, K., Martin, A. D., Gelmon, K. A., \& McKenzie, D. C. (2007). Resting energy expenditure and body mass changes in women during adjuvant chemotherapy for breast cancer. Cancer Nurs, 30(2), 95-100. https://doi.org/10.1097/01.NCC.0000265004.64440.5f

Chan, D. S. M., Vieira, A. R., Aune, D., Bandera, E. V., Greenwood, D. C., McTiernan, A., ... Norat, T. (2014). 
Body mass index and survival in women with breast cancer-systematic literature review and meta-analysis of 82 follow-up studies. Ann Oncol, 25(10), 1901-1914. https://doi.org/10.1093/annonc/mdu042

Chen, X., Lu, W., Gu, K., Chen, Z., Zheng, Y., Zheng, W., ... Shu, X. O. (2011). Weight change and its correlates among breast cancer survivors. Nutr Cancer, 63(4), 538-548. https://doi.org/10.1080/01635581.2011.539316

Da Silva, M., Weiderpass, E., Licaj, I., Lissner, L., \& Rylander, C. (2018). Excess body weight, weight gain and obesity-related cancer risk in women in Norway: the Norwegian Women and Cancer study. British Journal of Cancer, 119(5), 646-656.

De Vries, Y., Van Den Berg, M., De Vries, J., Boesveldt, S., De Kruif, J. T. C., Buist, N., ... Timmer-Bonte, J. (2017). Differences in dietary intake during chemotherapy in breast cancer patients compared to women without cancer. Supportive Care in Cancer, 25(8), 2581-2591.

Demark-Wahnefried, W., Peterson, B. L., Winer, E. P., Marks, L., Aziz, N., Marcom, P. K., ... Rimer, B. K. (2001). Changes in weight, body composition, and factors influencing energy balance among premenopausal breast cancer patients receiving adjuvant chemotherapy. Journal of Clinical Oncology, 19(9), 2381-2389.

Demark-Wahnefried, W., Rimer, B. K., \& Winer, E. P. (1997). Weight gain in women diagnosed with breast cancer. J Am Diet Assoc, 97(5), 519-526. https://doi.org/10.1016/s0002-8223(97)00133-8

Demark-Wahnefried, W., Winer, E. P., \& Rimer, B. K. (1993). Why women gain weight with adjuvant chemotherapy for breast cancer. J Clin Oncol, 11(7), 1418-1429. https://doi.org/10.1200/jco.1993.11.7.1418

Dow, K. H., Ferrell, B. R., Leigh, S., Ly, J., \& Gulasekaram, P. (1996). An evaluation of the quality of life among long-term survivors of breast cancer. Breast Cancer Res Treat, 39(3), 261-273. https://doi.org/10.1007/bf01806154

Dowsett, M., Cuzick, J., Ingle, J., Coates, A., Forbes, J., Bliss, J., .. Colleoni, M. (2010). Meta-analysis of breast cancer outcomes in adjuvant trials of aromatase inhibitors versus tamoxifen. Journal of Clinical Oncology, 28(3), 509-518.

Ewertz, M., Gray, K. P., Regan, M. M., Ejlertsen, B., Price, K. N., Thürlimann, B., ... Mouridsen, H. T. (2012). Obesity and risk of recurrence or death after adjuvant endocrine therapy with letrozole or tamoxifen in the breast international group 1-98 trial. J Clin Oncol, 30(32), 3967-3975. https://doi.org/10.1200/jco.2011.40.8666

Feng, H., Chen, H.-C., Chen, I.-C., Lin, C.-H., Lu, Y.-S., Kuo, W.-H., ... Chen, W.-W. (2018). Survey of diet and physical activity in new cases of young breast cancer patients in Taiwan. Annals of Oncology, 29, ix122-ix123.

Ferioli, M., Zauli, G., Martelli, A. M., Vitale, M., McCubrey, J. A., Ultimo, S., ... Neri, L. M. (2018). Impact of physical exercise in cancer survivors during and after antineoplastic treatments. Oncotarget, 9(17), 14005.

Gandhi, A., Copson, E., Eccles, D., Durcan, L., Howell, A., Morris, J., ... Evans, D. G. (2019). Predictors of weight gain in a cohort of premenopausal early breast cancer patients receiving chemotherapy. The Breast, $45,1-6$.

Gandhi, A., Copson, E., Eccles, D., Durcan, L., Howell, A., Morris, J., ... Harvie, M. (2019). Predictors of weight gain in a cohort of premenopausal early breast cancer patients receiving chemotherapy. Breast, 45 , 1-6. https://doi.org/10.1016/j.breast.2019.02.006

Goh, V. H. H., \& Hart, W. G. (2018). Excess fat in the abdomen but not general obesity is associated with poorer metabolic and cardiovascular health in premenopausal and postmenopausal Asian women. Maturitas, 107, 33-38.

Gomez, S. L., Yao, S., Kushi, L. H., \& Kurian, A. W. (2019). Is Breast Cancer in Asian and Asian American Women a Different Disease?. JNCI: Journal of the National Cancer Institute, 111(12), 1243-1244. https://doi.org/10.1093/jnci/djz091

Goodwin, P. J., Ennis, M., Pritchard, K. I., McCready, D., Koo, J., Sidlofsky, S., ... Redwood, S. (1999). Adjuvant treatment and onset of menopause predict weight gain after breast cancer diagnosis. J Clin Oncol, 17(1), 120-129. https://doi.org/10.1200/jco.1999.17.1.120

Gu, K., Chen, X., Zheng, Y., Chen, Z., Zheng, W., Lu, W., ... Shu, X. O. (2010). Weight change patterns among breast cancer survivors: results from the Shanghai breast cancer survival study. Cancer Causes \& Control, 
21(4), 621-629.

Gu, K., Chen, X., Zheng, Y., Chen, Z., Zheng, W., Lu, W., ... Shu, X. O. (2010). Weight change patterns among breast cancer survivors: results from the Shanghai breast cancer survival study. Cancer Causes Control, 21(4), 621-629. https://doi.org/10.1007/s10552-009-9491-z

Hamer, J., \& Warner, E. (2017). Lifestyle modifications for patients with breast cancer to improve prognosis and optimize overall health. Cmaj, 189(7), E268-E274.

Han, H. S., Lee, K. W., Kim, J. H., Kim, S. W., Kim, I. A., Oh, D. Y., ... Lee, J. S. (2009). Weight changes after adjuvant treatment in Korean women with early breast cancer. Breast Cancer Res Treat, 114(1), 147-153. https://doi.org/10.1007/s10549-008-9984-6

Harvie, M. N., Howell, A., Thatcher, N., Baildam, A., \& Campbell, I. (2005). Energy balance in patients with advanced NSCLC, metastatic melanoma and metastatic breast cancer receiving chemotherapy-a longitudinal study. British Journal of Cancer, 92(4), 673-680.

Heideman, W., Russell, N., Gundy, C., Rookus, M., \& Voskuil, D. (2009). The frequency, magnitude and timing of post-diagnosis body weight gain in Dutch breast cancer survivors. European Journal of Cancer, 45(1), 119-126.

Imayama, I., Alfano, C. M., Neuhouser, M. L., George, S. M., Wilder Smith, A., Baumgartner, R. N., ... McTiernan, A. (2013). Weight, inflammation, cancer-related symptoms and health related quality of life among breast cancer survivors. Breast Cancer Res Treat, 140(1), 159-176. https://doi.org/10.1007/s10549-013-2594-y

Irwin, M. L., McTiernan, A., Baumgartner, R. N., Baumgartner, K. B., Bernstein, L., Gilliland, F. D., ... Ballard-Barbash, R. (2005). Changes in body fat and weight after a breast cancer diagnosis: influence of demographic, prognostic, and lifestyle factors. $J$ Clin Oncol, 23(4), 774-782. https://doi.org/10.1200/jco.2005.04.036

Jung, G. H., Kim, J. H., \& Chung, M. S. (2020). Changes in weight, body composition, and physical activity among patients with breast cancer under adjuvant chemotherapy. European Journal of Oncology Nursing, $44,101680$.

Kapoor, E., Collazo-Clavell, M. L., \& Faubion, S. S. (2017). Weight gain in women at midlife: a concise review of the pathophysiology and strategies for management. Paper presented at the Mayo Clinic Proceedings.

Katan, M. B., \& Ludwig, D. S. (2010). Extra calories cause weight gain—but how much?. Jama, 303(1), 65-66.

Kroenke, C. H., Chen, W. Y., Rosner, B., \& Holmes, M. D. (2005). Weight, weight gain, and survival after breast cancer diagnosis. J Clin Oncol, 23(7), 1370-1378. https://doi.org/10.1200/jco.2005.01.079

Lankester, K., Phillips, J., \& Lawton, P. (2002). Weight gain during adjuvant and neoadjuvant chemotherapy for breast cancer: an audit of 100 women receiving FEC or CMF chemotherapy. Clinical Oncology, 14(1), 64-67.

Li, E., Guida, J. L., Tian, Y., Sung, H., Koka, H., Li, M., ... Guo, C. (2019). Associations between mammographic density and tumor characteristics in Chinese women with breast cancer. Breast Cancer Research and Treatment, 177(2), 527-536.

Ligibel, J. A., Basen-Engquist, K., \& Bea, J. W. (2019). Weight management and physical activity for breast cancer prevention and control. American Society of Clinical Oncology Educational Book, 39, e22-e33.

Liu, L.-N., Lin, Y.-C., Miaskowski, C., Chen, S.-C., \& Chen, M.-L. (2017). Association between changes in body fat and disease progression after breast cancer surgery is moderated by menopausal status. $B M C$ Cancer, 17(1), 1-7.

Lorizio, W., Wu, A. H., Beattie, M. S., Rugo, H., Tchu, S., Kerlikowske, K., \& Ziv, E. (2012). Clinical and biomarker predictors of side effects from tamoxifen. Breast Cancer Res Treat, 132(3), 1107-1118. https://doi.org/10.1007/s10549-011-1893-4

Makari-Judson, G., Braun, B., Jerry, D. J., \& Mertens, W. C. (2014). Weight gain following breast cancer diagnosis: implication and proposed mechanisms. World Journal of Clinical Oncology, 5(3), 272.

Min, Y. H., Lee, J. W., Chung, I. Y., \& Ahn, S. H. (2017). Longitudinal patterns and associated factors of postdiagnosis weight changes in Korean breast cancer survivors with normal body mass index. Supportive Care in Cancer, 25(8), 2549-2558. 
Misra, A., Soares, M. J., Mohan, V., Anoop, S., Abhishek, V., Vaidya, R., ... Pradeepa, R. (2018). Body fat, metabolic syndrome and hyperglycemia in South Asians. Journal of Diabetes and Its Complications, 32(11), 1068-1075.

Mutschler, N. S., Scholz, C., Friedl, T. W. P., Zwingers, T., Fasching, P. A., Beckmann, M. W., ... Rack, B. (2018). Prognostic impact of weight change during adjuvant chemotherapy in patients with high-risk early breast cancer: results from the adebar study. Clinical Breast Cancer, 18(2), 175-183. https://doi.org/10.1016/j.clbc.2018.01.008

Nichols, H. B., Trentham-Dietz, A., Egan, K. M., Titus-Ernstoff, L., Holmes, M. D., Bersch, A. J., ... Newcomb, P. A. (2009). Body mass index before and after breast cancer diagnosis: associations with all-cause, breast cancer, and cardiovascular disease mortality. Cancer Epidemiol Biomarkers Prev, 18(5), 1403-1409. https://doi.org/10.1158/1055-9965.Epi-08-1094

Nindrea, R. D., Aryandono, T., Lazuardi, L., \& Dwiprahasto, I. (2019). Association of overweight and obesity with breast cancer during premenopausal period in Asia: A meta-analysis. Int J Prev Med, 10, 192. https://doi.org/10.4103/ijpvm.IJPVM_372_18

Nyrop, K. A., Deal, A. M., Lee, J. T., Muss, H. B., Choi, S. K., Dixon, S., ... Shachar, S. S. (2017). Weight changes in postmenopausal breast cancer survivors over 2 years of endocrine therapy: a retrospective chart review. Breast Cancer Research and Treatment, 162(2), 375-388.

Nyrop, K. A., Deal, A. M., Lee, J. T., Muss, H. B., Choi, S. K., Wheless, A., ... Shachar, S. S. (2018). Weight gain in hormone receptor-positive (HR+) early-stage breast cancer: is it menopausal status or something else?. Breast Cancer Research and Treatment, 167(1), 235-248.

Ortiz-Mendoza, C. M., de-la-Fuente-Vera, T. A., \& Pérez-Chávez, E. (2014). Metabolic syndrome in Mexican women survivors of breast cancer: a pilot study at a general hospital. Med Arch, 68(1), 19-21. https://doi.org/10.5455/medarh.2014.68.19-21

Park, S., Lee, J. E., Yu, J., Paik, H.-J., Ryu, J. M., Kim, I., ... Nam, S. J. (2018). Risk factors affecting breast cancer-related lymphedema: serial body weight change during neoadjuvant anthracycline plus cyclophosphamide followed by taxane. Clinical Breast Cancer, 18(1), e49-e54.

Raghavendra, A., Sinha, A. K., Valle-Goffin, J., Shen, Y., Tripathy, D., \& Barcenas, C. H. (2018). Determinants of weight gain during adjuvant endocrine therapy and association of such weight gain with recurrence in long-term breast cancer survivors. Clin Breast Cancer, 18(1), e7-e13. https://doi.org/10.1016/j.clbc.2017.11.006

Reddy, S. M., Sadim, M., Li, J., Yi, N., Agarwal, S., Mantzoros, C. S., .. Kaklamani, V. G. (2013). Clinical and genetic predictors of weight gain in patients diagnosed with breast cancer. British Journal of Cancer, 109(4), 872-881. https://doi.org/10.1038/bjc.2013.441

Rock, C. L., \& Demark-Wahnefried, W. (2002). Nutrition and survival after the diagnosis of breast cancer: a review of the evidence. J Clin Oncol, 20(15), 3302-3316. https://doi.org/10.1200/jco.2002.03.008

Rock, C. L., Flatt, S. W., Newman, V., Caan, B. J., Haan, M. N., Stefanick, M. L., ... Pierce, J. P. (1999). Factors associated with weight gain in women after diagnosis of breast cancer. Journal of the American Dietetic Association, 99(10), 1212-1221. https://doi.org/10.1016/S0002-8223(99)00298-9

Sander, A. P., Wilson, J., Izzo, N., Mountford, S. A., \& Hayes, K. W. (2012). Factors that affect decisions about physical activity and exercise in survivors of breast cancer: a qualitative study. Physical Therapy, 92(4), 525-536.

Saquib, N., Flatt, S. W., Natarajan, L., Thomson, C. A., Bardwell, W. A., Caan, B., ... Pierce, J. P. (2007). Weight gain and recovery of pre-cancer weight after breast cancer treatments: evidence from the women's healthy eating and living (WHEL) study. Breast Cancer Res Treat, 105(2), 177-186. https://doi.org/10.1007/s10549-006-9442-2

Saquib, N., Flatt, S. W., Natarajan, L., Thomson, C. A., Bardwell, W. A., Caan, B., ... Pierce, J. P. (2007). Weight gain and recovery of pre-cancer weight after breast cancer treatments: evidence from the women's healthy eating and living (WHEL) study. Breast Cancer Research and Treatment, 105(2), 177-186.

Schiavon, G., \& Smith, I. E. (2014). Status of adjuvant endocrine therapy for breast cancer. Breast Cancer Research, 16(2), 1-17.

Schmidt, M. E., Wiskemann, J., \& Steindorf, K. (2018). Quality of life, problems, and needs of disease-free 
breast cancer survivors 5 years after diagnosis. Quality of Life Research, 27(8), 2077-2086.

Schvartsman, G., Gutierrez-Barrera, A. M., Song, J., Ueno, N. T., Peterson, S. K., \& Arun, B. (2017). Association between weight gain during adjuvant chemotherapy for early-stage breast cancer and survival outcomes. Cancer Med, 6(11), 2515-2522. https://doi.org/10.1002/cam4.1207

Sedjo, R. L., Byers, T., Ganz, P. A., Colditz, G. A., Demark-Wahnefried, W., Wolin, K. Y., ... Rock, C. L. (2014). Weight gain prior to entry into a weight-loss intervention study among overweight and obese breast cancer survivors. Journal of Cancer Survivorship, 8(3), 410-418.

Shang, L., Hattori, M., Fleming, G., Jaskowiak, N., Hedeker, D., Olopade, O. I., ... Huo, D. (2021). Impact of post-diagnosis weight change on survival outcomes in Black and White breast cancer patients. Breast Cancer Research, 23(1), 1-15.

Siegel, R. L., Miller, K. D., \& Jemal, A. (2020). Cancer statistics, 2020. CA: A Cancer Journal for Clinicians, 70(1), 7-30. https://doi.org/10.3322/caac.21590

Tessomboon, K., \& Chompoonuch, S. (2019). Prevalence and associated factors of weight gain after early breast cancer diagnosis. Annals of Oncology, 30, vi137.

Trédan, O., Bajard, A., Meunier, A., Roux, P., Fiorletta, I., Gargi, T., ... Faure, C. (2010). Body weight change in women receiving adjuvant chemotherapy for breast cancer: a French prospective study. Clinical Nutrition, 29(2), 187-191.

Trédan, O., Bajard, A., Meunier, A., Roux, P., Fiorletta, I., Gargi, T., ... Bachmann, P. (2010). Body weight change in women receiving adjuvant chemotherapy for breast cancer: a French prospective study. Clin Nutr 29(2), 187-191. https://doi.org/10.1016/j.clnu.2009.08.003

Tremblay, M. S., Pérez, C. E., Ardern, C. I., Bryan, S. N., \& Katzmarzyk, P. T. (2005). Obesity, overweight and ethnicity. Health Rep, 16(4), 23-34.

Vagenas, D., DiSipio, T., Battistutta, D., Demark-Wahnefried, W., Rye, S., Bashford, J., ... Hayes, S. C. (2015). Weight and weight change following breast cancer: evidence from a prospective, population-based, breast cancer cohort study. BMC Cancer, 15(1), 1-9.

Van den Berg, M. M. G. A., Winkels, R. M., De Kruif, J. T. C. M., Van Laarhoven, H. W. M., Visser, M., De Vries, J. H. M., ... Kampman, E. (2017). Weight change during chemotherapy in breast cancer patients: a meta-analysis. BMC Cancer, 17(1), 259. https://doi.org/10.1186/s12885-017-3242-4

Van den Berg, M., Winkels, R., De Kruif, J. T. C., Van Laarhoven, H., Visser, M., De Vries, J., ... Kampman, E. (2017). Weight change during chemotherapy in breast cancer patients: a meta-analysis. BMC Cancer, 17(1), $1-13$.

Vance, V., Mourtzakis, M., McCargar, L., \& Hanning, R. (2011). Weight gain in breast cancer survivors: prevalence, pattern and health consequences. Obesity Reviews, 12(4), $282-294$. https://doi.org/10.1111/j.1467-789X.2010.00805.x

Vargas-Meza, A., Chavez-Tostado, M., Cortes-Flores, A., Urias-Valdez, D., Delgado-Gomez, M., Morgan-Villela, G., ... Fuentes-Orozco, C. (2017). Body weight changes after adjuvant chemotherapy of patients with breast cancer: results of a Mexican cohort study. European Journal of Cancer Care, 26(5), e12550.

Verhaegen, A. A., \& Van Gaal, L. F. (2019). Drugs that affect body weight, body fat distribution, and metabolism. Endotext [Internet].

Wang, J. S., Cai, H., Wang, C. Y., Zhang, J., \& Zhang, M. X. (2014). Body weight changes in breast cancer patients following adjuvant chemotherapy and contributing factors. Mol Clin Oncol, 2(1), 105-110. https://doi.org/10.3892/mco.2013.209

Wen, C. P., David Cheng, T. Y., Tsai, S. P., Chan, H. T., Hsu, H. L., Hsu, C. C., ... Eriksen, M. P. (2009). Are Asians at greater mortality risks for being overweight than Caucasians? Redefining obesity for Asians. Public Health Nutr, 12(4), 497-506. https://doi.org/10.1017/s1368980008002802

World Health Organization, \& Regional Office for the Western, P. (2000). The Asia-Pacific perspective: redefining obesity and its treatment: Sydney: Health Communications Australia.

Yeo, W., Mo, F. K. F., Pang, E., Suen, J. J. S., Koh, J., Loong, H. H. F., ... Liem, G. S. (2017). Profiles of lipids, blood pressure and weight changes among premenopausal Chinese breast cancer patients after adjuvant 
chemotherapy. BMC Women's Health, 17(1), 55. https://doi.org/10.1186/s12905-017-0409-8

Yip, C. H. (2009). Breast cancer in Asia. Methods Mol Biol, 471, 51-64. https://doi.org/10.1007/978-1-59745-416-2_3

\section{Copyrights}

Copyright for this article is retained by the author(s), with first publication rights granted to the journal.

This is an open-access article distributed under the terms and conditions of the Creative Commons Attribution license (http://creativecommons.org/licenses/by/4.0/). 